\title{
Mortality of butchers and cooks identified from the 1961 census of England and Wales
}

\author{
David Coggon, Graham Wield
}

\begin{abstract}
Objectives-To explore a suspected hazard of lung cancer in butchers and cooks. Methods-4018 male butchers and 2062 male cooks were identified from the 1961 census of England and Wales. 4857 (79.9\%) of these men were traced through the National Health Service Central Register, and 3518 deaths were recorded during follow up to the end of 1992 . Mortality from lung cancer and other causes was compared with that of the general population by the person-years method.
\end{abstract}

Results-Mortality from all causes was significantly below that of the national population in both butchers (standardised mortality ratio (SMR) $0.94,95 \%$ confidence interval (95\% CI) $0.90-0.98)$ and cooks (SMR 0.89, 95\% CI 0.84-0.95). When allowance was made for a latency of 20 years from entry to follow up, the deficit in butchers was reduced, but that in cooks persisted, and was largely explained by a shortfall of deaths from cancer and circulatory disease. Mortality from lung cancer was close to expectation in the butchers (SMR 1.01, 95\% CI 0.90-1.13) and below expectation in the cooks (SMR 0.93, 95\% CI 0.75-1.13). Cooks had increased mortality from cancers of the oral cavity (SMR 5.57) and pharynx (SMR 2・66).

Conclusions-The findings provide no support for an occupational hazard of lung cancer in either butchers or cooks. The possibility of excess risk in subgroups of these occupations cannot be discounted. The high rates of oral and pharyngeal cancer in cooks are probably a consequence of high alcohol consumption.

(Occup Environ Med 1995;52:157-159)

MRC Environmental Epidemiology Unit, University of

Southampton, Southampton, General Hospital Southampton D Coggon G Wield

Correspondence to: Dr D Coggon, MRC Environmental Epidemiology Unit, University of Southampton, Southampton General Hospital Southampton SO16 6YD.

Accepted 24 November 1994
Sweden.' Subsequently, cohort studies of meat workers in the United States ${ }^{56}$ and Britain $^{7}$ also showed excesses of lung cancer.
In the American investigation, risk was highest in employees at meat packing plants, which suggests that fumes from the plastics used to wrap meat might be responsible. On the other hand, the British study found highest mortality in abattoir workers handling freshly slaughtered meat, and it was proposed that the tumours might be caused by a papillomavirus as butchers are known to have an unusually high prevalence of hand warts. ${ }^{8} \mathrm{~A}$ confounding effect of smoking could also have contributed to the excesses of lung cancer in these studies.

Like butchers, cooks have had increased mortality from lung cancer in routine analyses of occupational mortality, ${ }^{3911}$ and these findings are supported by a study of cancer registrations by occupation in California ${ }^{12}$ and by two case-control investigations. ${ }^{1314}$ Also, a cohort study of retired cooks from the British army found significant excess mortality from lung cancer compared with the national population. ${ }^{15}$ Again, high rates of smoking may have contributed, but it is also possible that the fumes generated by cooking, particularly when food is fried, contain carcinogens. ${ }^{1617}$

To examine further the risk of lung cancer in butchers and cooks, we have carried out a retrospective cohort study of men who reported working in these occupations at the 1961 census of England and Wales.

\section{Methods}

As part of the national census of England and Wales carried out on 23 and 24 April 1961, details of current occupation were collected for a $10 \%$ sample of the population. Men who were working as butchers or cooks were identified from these records, and the name, date of birth, and place of residence of each was abstracted. This information was then used to trace subjects through the National Health Service (NHS) Central Register up to 31 December 1992. Traces were classed as definite (with an exact match for date of birth) or probable (date of birth not matched exactly). These probable dates occurred because at the 1961 census many subjects gave only their age in years and months rather than a full date of birth. In some cases even this information was unavailable or inaccurate, and no tracing was possible. For reasons of confidentiality, the identification and tracing of subjects was carried out by the Office of Population Censuses and Surveys (OPCS) who provided us with an anonymised record for each man giving his date of birth (exact or approximate), 
Table 1 Outcome of follow-up

\begin{tabular}{lcr}
\hline & Butchers & Cooks \\
\hline Untraced & 646 & 577 \\
Probably traced: & 909 & 485 \\
Alive at 31 12 92 & 204 & 192 \\
Deceased & 701 & 271 \\
Emigrated & 1 & 16 \\
Otherwise lost to follow up & 3 & 6 \\
Definitely traced: & 2463 & 1000 \\
Alive at 31 12 92 & 527 & 321 \\
Deceased & 1910 & 636 \\
Emigrated & 24 & 31 \\
Otherwise lost to follow up & 2 & 12 \\
Total & 4018 & 2062 \\
\hline
\end{tabular}

occupation in 1961, date of death, or loss to follow up-for example, through emigration-reason for loss to follow up, underlying cause of death (coded to the ninth revision of the International Classification of Diseases (ICD-9)), and whether the trace was definite or probable. For probable traces who had died, we were also given the most recent full time occupation as recorded on the death certificate.

The mortality of each occupational group from lung cancer and other causes was compared with that of the national population by the person-years method with stratification of age and calendar period in five-year intervals. Confidence intervals (CIs) for standardised mortality ratios (SMRs) were based on the Poisson distribution.

\section{Results}

The search of census returns from 1961 identified 4018 male butchers and 2062 male cooks. Of these 6080 men, 3463 (57\%) were

Table 2 Mortality of butchers and cooks 1961-92

\begin{tabular}{|c|c|c|c|c|}
\hline \multirow[b]{2}{*}{ Cause of death (ICD-9 codes) } & \multicolumn{2}{|l|}{ Butchers } & \multicolumn{2}{|l|}{ Cooks } \\
\hline & $\begin{array}{l}\text { Deaths } \\
\text { observed }\end{array}$ & $S M R(95 \% C I)$ & $\begin{array}{l}\text { Deaths } \\
\text { observed }\end{array}$ & $\operatorname{SMR}(95 \% \mathrm{CI})$ \\
\hline All causes (001-999) & 2611 & $0.94(0.90-0.98)$ & 907 & $0.89(0.84-0.95)$ \\
\hline All cancer $(140-208)$ & 691 & $0.96(0.89-1.04)$ & 233 & $0.87(0.76-0.99)$ \\
\hline Cancer of oral cavity (143-145) & 1 & $0.55(0.01-3.08)$ & 4 & $5.57(1.52-14 \cdot 26)$ \\
\hline Cancer of pharynx (146-149.1) & 2 & $0.53(0.06-1.91)$ & 4 & $2.66(0.73-6.81)$ \\
\hline Cancer of oesophagus (150) & 15 & $0.71(0.40-1 \cdot 17)$ & 3 & $0.36(0.07-1.05)$ \\
\hline Cancer of stomach (15i) & 72 & $0.99(0.77-1.24)$ & 26 & $0.99(0.65-1.45)$ \\
\hline Cancer of colon (153) & 38 & $0.84(0.59-1.15)$ & 17 & $1.00(0.59-1.61)$ \\
\hline Cancer of rectum (154) & 39 & $1.23(0.87-1.67)$ & 11 & $0.93(0.46-1.66)$ \\
\hline Cancer of liver $(155 \cdot 0-155 \cdot 1)$ & 2 & $0.47(0.06-1.71)$ & 2 & $1 \cdot 14(0 \cdot 14-4 \cdot 13)$ \\
\hline Cancer of gall bladder (156) & 4 & $1.00(0.27-2.57)$ & 0 & $0.00(0.00-2.52)$ \\
\hline Cancer of pancreas (157) & 26 & $0.88(0.57-1.29)$ & 9 & $0.81(0.37-1.53)$ \\
\hline Cancer of larynx (161) & 5 & $0.80(0.26-1.85)$ & 2 & $0.83(0.10-2.98)$ \\
\hline Cancer of lung (162-164) & 294 & $1.01(0.90-1.13)$ & 100 & $0.93(0.75-1.13)$ \\
\hline Melanoma of skin (172) & 4 & $1.74(0.47-4.46)$ & 0 & $0.00(0.00-3.65)$ \\
\hline Cancer of prostate (185) & 71 & $1.21(0.95-1.53)$ & 10 & $0.49(0.24-0.90)$ \\
\hline Cancer of bladder (188) & 34 & $1.06(0.73-1.48)$ & 12 & $1.04(0.54-1.82)$ \\
\hline Cancer of kidney (189) & 12 & $1.08(0.56-1.88)$ & 5 & $1.13(0.37-2.64)$ \\
\hline Cancer of brain (191-192) & 5 & $0.54(0.17-1.25)$ & 2 & $0.47(0.06-1.72)$ \\
\hline Hodgkin's disease (201) & 2 & $0.77(0.09-2.78)$ & 2 & $1 \cdot 84(0 \cdot 22-6 \cdot 63)$ \\
\hline $\begin{array}{l}\text { Non-Hodgkin's lymphoma } \\
(200,202)\end{array}$ & 7 & $0.66(0.27-1.37)$ & 2 & $0.47(0.06-1.72)$ \\
\hline Multiple myeloma (203) & 5 & $0.62(0.20-1.46)$ & 1 & $0.33(0.01-1.83)$ \\
\hline Leukaemia (204-208) & 8 & $0.54(0.23-1.06)$ & 6 & $1.07(0.39-2.32)$ \\
\hline $\begin{array}{c}\text { Infective and parasitic diseases } \\
(001-007,010-139)\end{array}$ & 10 & $0.69(0.33-1.26)$ & 5 & $0.91(0.30-2 \cdot 13)$ \\
\hline $\begin{array}{l}\text { Endocrine, nutritional, and } \\
\text { metabolic diseases }(240-279)\end{array}$ & 46 & $1 \cdot 60(1 \cdot 17-2 \cdot 13)$ & 19 & $1.81(1.09-2 \cdot 83)$ \\
\hline Blood diseases $(280-289)$ & 5 & $1.00(0.32-2 \cdot 33)$ & 1 & $0.57(0.01-3.15)$ \\
\hline Mental disorders (290-315) & 20 & $0.93(0.57-1.43)$ & 6 & $0.83(0.31-1.81)$ \\
\hline $\begin{array}{l}\text { Diseases of the nervous system } \\
(320-389)\end{array}$ & 37 & $1.06(0.75-1.46)$ & 10 & $0.79(0.38-1.45)$ \\
\hline Circulatory disease $(390-459)$ & 1271 & $0.92(0.87-0.97)$ & 437 & $0.87(0.79-0.95)$ \\
\hline Respiratory disease $(460-519)$ & 346 & $0.88(0.79-0.98)$ & 129 & $0.95(0.80-1.13)$ \\
\hline $\begin{array}{l}\text { Digestive disease (008-009, } \\
520-579)\end{array}$ & 62 & $0.91(0 \cdot 70-1 \cdot 17)$ & 29 & $1 \cdot 16(0 \cdot 77-1 \cdot 66)$ \\
\hline Injury and poisoning (800-999) & 36 & $0.66(0.47-0.92)$ & 19 & $0.84(0.50-1.31)$ \\
\hline
\end{tabular}

definitely traced and 1394 (23\%) probably traced at the NHS Central Register. Table 1 summarises the outcome of follow up separately for butchers and cooks. Among the 701 butchers who were probably traced and found to be deceased, $570(81 \%)$ were recorded as meat workers on their death certificates. Among the cooks who had died 187/271 $(69 \%)$ of the probable traces were described as cooks on their death certificates, and a further $16(6 \%)$ as working in other catering jobs.

Table 2 shows the patterns of mortality in an analysis that included both definite and probable traces. All causes of mortality was significantly below expectation in both butchers (SMR 0.94, 95\% CI 0.90-0.98) and cooks (SMR 0.89, 95\% CI 0.84-0.95). When the analysis was restricted to the period 24 April 1981 to 31 December 1992 - that is, allowing for a 20 year latency from entry to the studythe deficit of deaths in butchers was reduced (SMR 0.98, 95\% CI 0.93-1.04), but that in cooks persisted (SMR 0.87, 95\% CI $0.78-0.96)$.

Among the butchers, mortality during 1961 to 1992 from all cancers (SMR 0.96) and specifically from lung cancer (SMR 1.01) was close to that expected. The only disease category for which death rates were significantly increased was endocrine, nutritional, and metabolic diseases (SMR $1.60,95 \%$ CI $1 \cdot 17-2 \cdot 13), 42$ of the 46 observed deaths being from diabetes mellitus.

The cooks had a significantly low mortality from all cancer (SMR 0.87, 95\% CI 0.76-0.99), which was due in part to a lower rate of lung cancer than expected (SMR $0.93)$. There was also a large deficit of prostatic cancer (SMR 0.49, 95\% CI 0.24-0.90). Excess mortality was observed for several tumours related to alcohol including cancers of the oral cavity (SMR 5.57) and pharynx (SMR 2.66), but not oesophageal cancer (SMR 0.36). Among the non-neoplastic disease categories, the only significant excess of deaths was again from endocrine, nutritional, and metabolic diseases (SMR 1.81, 95\% CI $1 \cdot 09-2 \cdot 83$ ). Seventeen of the 19 deaths in this category were from diabetes mellitus. There was a significant deficit of deaths from circulatory disease (SMR 0.87, 95\% CI 0.79-0.95).

Repeat analyses restricted to the 2463 butchers and 1000 cooks who were definitely traced produced similar results except that there was a slight (non-significant) excess of lung cancer in cooks (SMR 1.06).

\section{Discussion}

This study provides no support for earlier investigations that have suggested a hazard of lung cancer in butchers ${ }^{1-7}$ and cooks. ${ }^{39-15}$ Many of the subjects included in these earlier studies would have worked as butchers or cooks in the same era as the men whom we studied, and the reasons for the discordant results are unclear.

One possible source of bias was the incompleteness of tracing that resulted from 
imprecision in dates of birth as recorded at the census. Only $57 \%$ of subjects were definitely traced, whereas a further $23 \%$ were considered to be probably traced on the basis of a partial match for date of birth. Most of the probable traces are likely to have been correct, as most of those who had died were recorded as butchers or cooks on their death certificates. Results were similar whether or not the probable traces were included in the analysis. The failure to trace at all some $20 \%$ of subjects was again largely a consequence of incomplete data collection at the census, and there is no reason to expect that it would relate to subsequent mortality. It is unlikely, therefore, that the incomplete follow up would have obscured an important excess of lung cancer.

Another limitation of the census being a starting point for the study was the lack of information about how long subjects worked as butchers or cooks. From the occupations recorded on the death certificates of probable traces, it seems that most men worked in these occupations long term. Furthermore, excess lung cancer in butchers and cooks has been found previously in cross sectional analyses of occupational mortality based on censuses. ${ }^{3910}$ This suggests that the negative findings cannot be explained by inclusion of a high proportion of transient workers who then moved on to other jobs.

Overall mortality was lower than expected in both occupations, but the deficit in butchers was reduced after allowance for a 20 year latency from entry to follow up. This would be compatible with a healthy worker effect. On the other hand, deaths in cooks were significantly below expectation even after a latent interval of 20 years. The low SMR was attributable particularly to deficits of cancer and circulatory disease, which contrasts notably with the observation that coronary heart disease was unusually common in retired cooks from the British army. ${ }^{15}$ Whatever was responsible for the high rate of coronary heart disease in military cooks does not seem to affect the occupation as a whole.

The high mortality of cooks from cancers of the oral cavity and pharynx was probably attributable to alcohol, which is known to cause both of these tumours. ${ }^{18}$ Many cooks have ready access to alcohol through their work, and cooks have been reported in other studies to have a high incidence of diseases related to alcohol. ${ }^{10} 15$
Both butchers and cooks had increased death rates from diabetes mellitus, but mortality is a poor index of incidence of this disease, and may have been biased by change in practice for coding causes of death. Obesity is an established risk factor for non-insulin dependent diabetes, ${ }^{19}$ but it is not known whether the men studied had an unusually high prevalence of obesity.

Overall, the study does not provide evidence of any important occupational hazards that affect mortality in butchers or cooks. If these occupations do have an increased risk of lung cancer, then it may be concentrated among subgroups such as butchers handling freshly slaughtered meat and cooks who do a lot of frying, rather than in the occupations as a whole.

This study was conceived and initiated by the late Dr Michael Alderson, and was supported by a grant from the Cancer Research Campaign. We thank the staff of OPCS for their help in identifying and tracing subjects.

1 Fox AJ, Lynge E, Malker H. Lung cancer in butchers. Lancet 1982;i:165-6.

2 Wynne Griffith G. Lung cancer in butchers. Lancet 1982; i:399.

3 Office of Population Censuses and Surveys. Occupational mortality: decennial supplement 1979-80, 1982-83. London: HMSO, 1986. (Series DS No 6.)

4 Lynge E, Anderson O, Kristensen TS. Lung cancer in Danish butchers. Lancet 1983;i:527-8.

5 Johnson ES, Fischman HR, Matonoski GM, Diamond E. Cancer mortality among white males in the meat indusCancer mortality among white male

6 Johnson ES, Fischman HR, Matonoski GM, Diamond E. Occurrence of cancer in women in the meat industry. $\mathrm{Br}$ f Ind Med 1986;43:597-604.

7 Coggon D, Pannett B, Pippard EC, Winter PD. Lung cancer in the meat industry. $\mathrm{Br} \mathcal{F}$ Ind Med 1989;46:188-91.

8 Keefe M, Al Ghamdi A, Coggon D, Maitland NJ, Eggar P, Keefe CJ, et al. Cutaneous warts in butchers. $B r \mathcal{F}$ Dermatol 1994;130:9-14.

9 Registrar General. Decennial supplement England and Wales 1961: occupational mortality. London: HMSO, 1971.

10 Office of Population Censuses and Surveys. Occupational mortality decennial supplement 1970-1972 England and mortality decennial supplement

11 Danmarks statistik. Dodelighed 1970-80 (mortality 1970-80). Copenhagen. Danmarks statistik, 1985.

12 Menck HR, Henderson BE. Occupational differences in rates of lung cancer. $\mathcal{F}$ Occup Med 1976;18:797-801.

13 Coggon D, Pannett B, Acheson ED. Use of job-exposure matrix in occupational analysis of lung and bladder cancers on the basis of death certificates. $\mathcal{F}$ Natl Cancer Inst 1984;72:61-5.

14 Coggon D, Pannett B, Osmond C, Acheson ED. A survey of cancer and occupation in young and middle aged men: 1 , cancers of the respiratory tract. $B r F$ Ind Med 1986;43:332-8.

15 Coggon D, Wield G. Mortality of army cooks. Scand 7 Work Environ Health 1993;19:85-8.

16 Rappaport SM, McCartney MC, Wei ET. Volatilization of mutagens from beef during cooking. Cancer Lett 1979; mutagens

17 Qu YH, Xu GX, Huang F, Fang JC, Gao YT. An Ames test on other by-products of the heating of cooking oils. Tumor 1986;6:58-60

18 Tuyns AJ. Alcohol. In: Schottenfeld D, Fraumeni JF, eds. Cancer epidemiology and prevention. Philadelphia: WB Saunders, 1982:293-303.

19 Björntorp P. Regional fat distribution-implications for type 2 diabetes. Int $\mathcal{F}$ Obesity 1992;16:519-27. 